Pacific Journal of Mathematics

A GENERALIZED COROLLARY OF THE BROWDER-KIRK
FIXED POINT THEOREM 


\section{A GENERALIZED COROLLARY OF THE BROWDER-KIRK FIXED POINT THEOREM}

By W. G. Dotson, Jr. and W. Robert ManN

This paper generalizes a corollary, due to W. A. Kirk, of the F. E. Browder-W. A. Kirk fixed point theorem for nonexpansive self-mappings of closed, bounded, convex sets in uniformly convex Banach spaces.

F. E. Browder [1] and W. A. Kirk [4] have independently proved that if $F$ is a closed, bounded, convex subset of a uniformly convex Banach space, and if $T$ is a nonexpansive mapping from $F$ into $F$, then $T$ has a fixed point in $F$. The following corollary was proved by Kirk [4] and also by Browder and Petryshyn [2]: If $E$ is a uniformly convex Banach space, and $T: E \rightarrow E$ is a nonexpansive mapping, and if for some $x_{1} \in E$ the sequence $\left\{T^{n} x_{1}\right\}$ of Picard iterates of $T$ is bounded, then $T$ has a fixed point in $E$. Browder and Petryshyn also observed that if the nonexpansive mapping $T$ has a fixed point in $E$, then for any $x_{1} \in E$ the sequence $\left\{T^{n} x_{1}\right\}$ will be bounded. Outlaw and Groetsch [6] have recently announced the following extension of this corollary: If $E$ is a uniformly convex Banach space, and $T: E \rightarrow E$ is a nonexpansive mapping, and $S_{\lambda}=\lambda I+(1-\lambda) T$ for a given $\lambda, 0<\lambda<1$, then $T$ has a fixed point in $E$ if and only if the sequence $\left\{S_{\lambda}^{n} x_{1}\right\}$ of Picard iterates of $S_{\lambda}$ is bounded for each $x_{1} \in E$. The purpose of this note is to show that this corollary and its extension are both special cases of a considerably more general corollary of the Browder-Kirk theorem.

W. R. Mann [5] introduced the following general iterative process: Suppose $A=\left[a_{n p}\right]$ is an infinite real matrix satisfying (1) $a_{n p} \geqq 0$ for all $n, p$, and $a_{n p}=0$ for $p>n$; (2) $\sum_{p=1}^{n} a_{n p}=1$ for each $n$; (3) $\lim _{n} a_{n p}=0$ for each $p$. If $F$ is a closed convex subset of a Banach space $E$, and $T: F \rightarrow F$ is a continuous mapping, and $x_{1} \in F$, then the process $M\left(x_{1}, A, T\right)$ is defined by

$$
v_{n}=\sum_{p=1}^{n} a_{n p} x_{p}, \quad x_{n+1}=T v_{n}, \quad n=1,2,3, \cdots .
$$

Various choices of the matrix $A$ yield many interesting iterative processes as special cases. With $A$ the infinite identity matrix, one gets the Picard iterates of $T: v_{n+1}=x_{n+1}=T v_{n}$, whence $v_{n+1}=T^{n} v_{1}=$ $T^{n} x_{1}$. With $0<\lambda<1$ and $A=\left[a_{n p}\right]$ defined by $a_{n p}=\lambda^{n-1}$ if $p=1$, $a_{n p}=\lambda^{n-p}(1-\lambda)$ if $1<p \leqq n, a_{n p}=0$ if $p>n, n=1,2,3, \cdots$, one gets $v_{n+1}=\lambda v_{n}+(1-\lambda) T v_{n}=S_{\lambda} v_{n}$, whence $v_{n+1}=S_{\lambda}^{n} v_{1}=S_{\lambda}^{n} x_{1}$. If $T$ is linear then an appropriate choice of $A$ yields 


$$
v_{n+1}=\left(x_{1}+T x_{1}+\cdots+T^{n} x_{1}\right) /(n+1),
$$

thus providing a connection with mean ergodic theorems for linear operators. Another choice of $A$ yields an iterative process recently investigated by Halpern [3], provided $x_{1}=0$. Many other choices are possible, of course. Our main theorem is as follows.

THEOREM 1. If $E$ is a uniformly convex Banach space, and if $T: E \rightarrow E$ is a nonexpansive mapping, and if there exist $x_{1} \in E$ and a process $M\left(x_{1}, A, T\right)$ such that either of the sequences $\left\{x_{n}\right\},\left\{v_{n}\right\}$ is bounded, then $T$ has a fixed point in $E$.

To prove this, we will make use of the following lemma which is a straightforward consequence of uniform convexity.

LEMma 1. Suppose $E$ is a uniformly convex Banach space, and suppose $r>0$. For each $\varepsilon>0$ let $p_{\varepsilon}=\sup \{s: s=\|u-v\|$ where $u, v \in E,\|u\|=2 r, 2 r<\|v\| \leqq 2 r+\varepsilon$, and $\|(1-t) u+t v\|>2 r$ for all $t \in(0,1)\}$. Given any $c>0$, there exists $\varepsilon>0$ such that $p_{\varepsilon} \leqq c$.

Proof of Theorem 1. We first observe that if either of the sequences $\left\{x_{n}\right\},\left\{v_{n}\right\}$ in the process $M\left(x_{1}, A, T\right)$ is bounded, then the other is also bounded. For if $\left\|x_{n}\right\| \leqq b$ for all $n$, then

$$
\left\|v_{n}\right\|=\left\|\sum_{p=1}^{n} a_{n p} x_{p}\right\| \leqq \sum_{p=1}^{n} a_{n p}\left\|x_{p}\right\| \leqq b \sum_{p=1}^{n} a_{n p}=b
$$

for all $n$; and if $\left\|v_{n}\right\| \leqq b$ for all $n$, then

$$
\left\|x_{n+1}-T(0)\right\|=\left\|T\left(v_{n}\right)-T(0)\right\| \leqq\left\|v_{n}-0\right\| \leqq b
$$

for all $n$. So, given $x_{1} \in E$ and a process $M\left(x_{1}, A, T\right)$ in which both of the sequences $\left\{x_{n}\right\},\left\{v_{n}\right\}$ are bounded, we wish to show that $T$ has a fixed point. This will be done by showing that $T$ maps a certain bounded, closed, convex set into itself. We use the notation $D_{r}(p)=$ $\{x:\|x-p\| \leqq r\}, r>0, p \in E$. Let $r>0$ be such that $x_{n} \in D_{r}(0)$ and $v_{n} \in D_{r}(0)$ for all $n$. For each $i=1,2,3, \cdots$, define sets $C_{i}$ and $G_{i}$ by

$$
C_{i}=\bigcap_{n=i}^{\infty} D_{2 r}\left(x_{n}\right), \quad G_{i}=\bigcap_{n=i}^{\infty}\left\{D_{2 r}\left(x_{n}\right) \cap D_{2 r}\left(v_{n}\right)\right\} .
$$

For each $i$, we have

$$
D_{r}(0) \subset G_{i} \subset C_{i} \subset D_{2 r}\left(x_{i}\right) \subset D_{3 r}(0) .
$$

Each $C_{i}$ and each $G_{i}$ is a nonempty bounded, closed, convex set, and it is clear that $C_{i} \subset C_{i+1}$ and $G_{i} \subset G_{i+1}$. We now show $T\left(G_{i}\right) \subset C_{i+1}$ : $x \in G_{i}$ implies $\left\|x-v_{n}\right\| \leqq 2 r$ for all $n \geqq i$, which gives $\left\|T x-T v_{n}\right\| \leqq$ 
$\left\|x-v_{n}\right\| \leqq 2 r$ for all $n \geqq i$; but, since $x_{n+1}=T v_{n}$, this can be written $\left\|T x-x_{n+1}\right\| \leqq 2 r$ for all $n \geqq i$, so that $T x \in C_{i+1}$. Define $\operatorname{sets} C$ and $G$ by

$$
C=\bigcup_{i=1}^{\infty} C_{i}, G=\bigcup_{i=1}^{\infty} G_{i} .
$$

Clearly, $D_{r}(0) \subset G \subset C \subset D_{3 r}(0)$; and $\bar{G}, \bar{C}$ are bounded, closed, convex sets. Since $T\left(G_{i}\right) \subset C_{i+1}$ for each $i$, we have $T(G) \subset C$. Since $T$ is continuous, $T(\bar{G}) \subset \overline{T(G)} \subset \bar{C}$. The proof will be completed by showing $C \subset \bar{G}$, so that $T(\bar{G}) \subset \bar{C} \subset \bar{G}$ (i.e., $T$ maps the bounded, closed, convex set $\bar{G}$ into itself). Since $C=\bigcup_{i=1}^{\infty} C_{i}$, it suffices to show that for each $i, C_{i} \subset \bar{G}$. Suppose $i$ is a given positive integer, and $x \in C_{i}$. We wish to show that $x \in \bar{G}$. The first step toward this end is set off as the following lemma.

LEMma 2. For each $\varepsilon>0$ there exists a positive integer $j_{\varepsilon} \geqq i$ such that $x \in \bigcap_{n=j_{\varepsilon}}^{\infty}\left\{D_{2 r}\left(x_{n}\right) \cap D_{2 r+\varepsilon}\left(v_{n}\right)\right\}=F_{j_{\varepsilon}}$.

Proof of Lemma 2. Since $x \in C_{i}$ we have $\left\|x-x_{p}\right\| \leqq 2 r$ for all $p \geqq i$. For all $n \geqq i$ we have

$$
\left\|x-v_{n}\right\|=\left\|\sum_{p=1}^{n} a_{n p} x-\sum_{p=1}^{n} a_{n p} x_{p}\right\|=\left\|\sum_{p=1}^{n} a_{n p}\left(x-x_{p}\right)\right\|
$$

so that

$$
\left\|x-v_{n}\right\| \leqq \sum_{p=1}^{n} a_{n p}\left\|x-x_{p}\right\|=\sum_{p=1}^{i-1} a_{n p}\left\|x-x_{p}\right\|+\sum_{p=i}^{n} a_{n p}\left\|x-x_{p}\right\|,
$$

whence, for all $n \geqq i$,

$$
\left\|x-v_{n}\right\| \leqq\left(\sum_{p=1}^{i-1} a_{n p}\right) \cdot \max _{1 \leqq p \leqq i-1}\left\|x-x_{p}\right\|+2 r .
$$

Since $i$ and $x$ are fixed, and since $\lim _{n} a_{n p}=0$ for each $p=1,2, \cdots, i-1$, it is clear that for any $\varepsilon>0$ there exists a positive integer $j_{\varepsilon} \geqq i$ such that $\left\|x-v_{n}\right\| \leqq 2 r+\varepsilon$ for all $n \geqq j_{\varepsilon}$. But $n \geqq j_{\varepsilon} \geqq i$ also implies $\left\|x-x_{n}\right\| \leqq 2 r$ since $x \in C_{i}$. Hence $n \geqq j_{s}$ implies

$$
x \in D_{2 r}\left(x_{n}\right) \cap D_{2 r+\varepsilon}\left(v_{n}\right),
$$

and so $x \in \bigcap_{n=j_{\varepsilon}}^{\infty}\left\{D_{2 r}\left(x_{n}\right) \cap D_{2 r+\varepsilon}\left(v_{n}\right)\right\}=F_{j_{\varepsilon}}$.

Proof of Theorem 1 continued. We return now to the final problem of showing $x \in \bar{G}$ (see immediately before Lemma 2). Given any $c>0$, choose $\varepsilon>0$ such that $p_{s} \leqq c$ (this can be done by Lemma 1 , in which $r>0$ is taken as the $r$ we are using in this proof). For 
this $\varepsilon$, there exists a positive integer $j_{\varepsilon} \geqq i$ such that $x \in F_{j_{\varepsilon}}$ (by Lemma 2). We will show $G_{j_{\varepsilon}} \cap D_{c}(x) \neq \phi$. Since $c$ is arbitrary, this will show $x \in \bar{G}=\left(\bigcup_{i=1}^{\infty} G_{i}\right)^{-}$. ${ }^{\varepsilon}$ We suppose $G_{j_{\varepsilon}} \cap D_{c}(x)=\phi$ and obtain a contradiction. Since $0 \in D_{r}(0) \subset G_{j_{\varepsilon}}, 0 \notin D_{c}(x)$, and so $0<c /\|x\|<1$. Let $t_{1}=1-(c /\|x\|)$. Then $0<t_{1}<1$ and $\left\|t_{1} x-x\right\|=\left(1-t_{1}\right)\|x\|=c$. Since $t_{1} x \in D_{c}(x)$, we have $t_{1} x \notin G_{j_{\varepsilon}}$. Now $x \in F_{j_{\varepsilon}} \subset \bigcap_{n=j_{\varepsilon}}^{\infty} D_{2 r}\left(x_{n}\right)=C_{j_{\varepsilon}}$, and since $C_{j_{\varepsilon}}$ also contains 0 and is convex, $t_{1} x \in C_{j_{\varepsilon}}$. Since $t_{1} x \notin G_{j_{\varepsilon}}$ and $t_{1} x \in C_{j_{\varepsilon}}$, we have $t_{1} x \notin \bigcap_{n=j_{\varepsilon}}^{\infty} D_{2 r}\left(v_{n}\right)$. Let $n$ be a positive integer, $n \geqq j_{\varepsilon}$, such that $t_{1} x \notin D_{2 r}\left(v_{n}\right)$. Let

$$
t_{2}=\sup \left\{t: 0<t<1 \text { and } t x \in D_{2 r}\left(v_{n}\right)\right\} \text {. }
$$

This set of $t$ 's is nonempty since $D_{r}(0) \subset D_{2 r}\left(v_{n}\right)$. Since $D_{2 r}\left(v_{n}\right)$ is closed, we have $t_{2} x \in D_{2 r}\left(v_{n}\right)$; and it is easily seen from the definition of $t_{2}$ that we must have $\left\|t_{2} x-v_{n}\right\|=2 r$. If $t_{2} \geqq t_{1}$, then, since 0 and $t_{2} x$ are in the convex set $D_{2 r}\left(v_{n}\right)$, we would have $t_{1} x \in D_{2 r}\left(v_{n}\right)$ which is not true. Hence $t_{2}<t_{1}$. Similarly we have $\left\|x-v_{n}\right\|>2 r$, since 0 is in the convex set $D_{2 r}\left(v_{n}\right)$ and $t_{1} x$ is not. Since $x \in F_{j_{\varepsilon}}$ and since $n \geqq j_{\varepsilon}, x \in D_{2 r+\varepsilon}\left(v_{n}\right)$, so we have $2 r<\left\|x-v_{n}\right\| \leqq 2 r+\varepsilon$. Next we observe that if $t \in(0,1)$

$$
\left\|(1-t)\left(t_{2} x-v_{n}\right)+t\left(x-v_{n}\right)\right\|=\left\|\left[(1-t) t_{2}+t \cdot 1\right] x-v_{n}\right\|>2 r
$$

since $t_{2}<(1-t) t_{2}+t \cdot 1<1$ so that $\left[(1-t) t_{2}+t \cdot 1\right] x \notin D_{2 r}\left(v_{n}\right)$. With $u=t_{2} x-v_{n}$ and $v=x-v_{n}$ we now have $\|u\|=2 r, 2 r<\|v\| \leqq$ $2 r+\varepsilon$, and $\|(1-t) u+t v\|>2 r$ for all $t \in(0,1)$. Hence $\|u-v\|=$ $\left\|t_{2} x-x\right\| \leqq p_{\varepsilon}$ (see Lemma 1 ). But $\varepsilon$ was chosen so that $p_{\varepsilon} \leqq c$. So we have

$$
\left\|t_{2} x-x\right\|=\left(1-t_{2}\right)\|x\| \leqq p_{\varepsilon} \leqq c .
$$

This gives $t_{2} \geqq 1-(c /\|x\|)=t_{1}$, which is a contradiction.

For completeness, we include the following theorem which is somewhat stronger than the converse of Theorem 1.

TheoRem 2. If $E$ is a normed linear space, and if $T: E \rightarrow E$ is a nonexpansive mapping, and if $T$ has a fixed point $p \in E$, then for any $x_{1} \in E$ and any process $M\left(x_{1}, A, T\right)$, the sequences $\left\{x_{n}\right\},\left\{v_{n}\right\}$ are bounded.

Proof. For each $n=1,2,3, \cdots$, we have

$$
\begin{aligned}
\left\|x_{n+1}-p\right\| & =\left\|T v_{n}-T p\right\| \leqq\left\|v_{n}-p\right\|=\left\|\sum_{j=1}^{n} a_{n j}\left(x_{j}-p\right)\right\| \\
& \leqq \sum_{j=1}^{n} a_{n j}\left\|x_{j}-p\right\| \leqq \max _{j=1, \ldots, n}\left\|x_{j}-p\right\| .
\end{aligned}
$$


Thus $\left\|x_{2}-p\right\| \leqq\left\|x_{1}-p\right\|,\left\|x_{3}-p\right\| \leqq \max _{j=1,2}\left\|x_{j}-p\right\|=\left\|x_{1}-p\right\|$, etc., so that we have $\left\|x_{j}-p\right\| \leqq\left\|x_{1}-p\right\|$ for all $j=1,2,3, \cdots$; and hence with $b=\left\|x_{1}-p\right\|+\|p\|$ we get $\left\|x_{j}\right\|=\left\|\left(x_{j}-p\right)+p\right\| \leqq$ $\left\|x_{j}-p\right\|+\|p\| \leqq b$ for all $j=1,2,3, \cdots$. Finally,

$$
\left\|v_{n}\right\|=\left\|\sum_{j=1}^{n} a_{n j} x_{j}\right\| \leqq \sum_{j=1}^{n} a_{n j}\left\|x_{j}\right\| \leqq b \cdot \sum_{j=1}^{n} a_{n j}=b
$$

for all $n=1,2,3, \cdots$.

\section{BIBLIOGRAPHY}

1. F. E. Browder, Nonexpansive nonlinear operators in a Banach space, Proc. Nat. Acad. Sci. U.S.A. 54 (1965), 1041-1044.

2. F. E. Browder and W. V. Petryshyn, The solution by iteration of nonlinear functional equations in Banach spaces, Bull. Amer. Math. Soc. 72 (1966), 571-575.

3. B. Halpern, Fixed points of nonexpanding maps, Bull. Amer. Math. Soc. 73 (1967), 957-961.

4. W. A. Kirk, A fixed point theorem for mappings which do not increase distances, Amer. Math. Monthly 72 (1965), 1004-1006.

5. W. Robert Mann, Mean value methods in iteration, Proc. Amer. Math. Soc. 4 (1953), 506-510.

6. C. L. Outlaw and C. W. Groetsch, Averaging iteration in a Banach space, Notices Amer. Math. Soc. 15 (1968), 180.

Received March 12, 1968.

North Carolina State University and

University of North Carolina, Chapel Hill 



\section{PACIFIC JOURNAL OF MATHEMATICS}

\section{EDITORS}

\section{H. ROYDEN}

Stanford University

Stanford, California

R. R. Phelps

University of Washington

Seattle, Washington 98105

\section{J. DugundJI}

Department of Mathematics

University of Southern California

Los Angeles, California 90007

RICHARD ARENS

University of California

Los Angeles, California 90024

\section{ASSOCIATE EDITORS}
E. F. BeCKENBACH
B. H. NeumanN
F. WOLF
K. YosIDA

\section{SUPPORTING INSTITUTIONS}

\author{
UNIVERSITY OF BRITISH COLUMBIA \\ CALIFORNIA INSTITUTE OF TECHNOLOGY \\ UNIVERSITY OF CALIFORNIA \\ MONTANA STATE UNIVERSITY \\ UNIVERSITY OF NEVADA \\ NEW MEXICO STATE UNIVERSITY \\ OREGON STATE UNIVERSITY \\ UNIVERSITY OF OREGON \\ OSAKA UNIVERSITY \\ UNIVERSITY OF SOUTHERN CALIFORNIA
}

\author{
STANFORD UNIVERSITY \\ UNIVERSITY OF TOKYO \\ UNIVERSITY OF UTAH \\ WASHINGTON STATE UNIVERSITY \\ UNIVERSITY OF WASHINGTON \\ AMERICAN MATHEMATICAL SOCIETY \\ CHEVRON RESEARCH CORPORATION \\ TRW SYSTEMS \\ NAVAL WEAPONS CENTER
}

Mathematical papers intended for publication in the Pacific Journal of Mathematics should be in typed form or offset-reproduced, double spaced with large margins. Underline Greek letters in red, German in green, and script in blue. The first paragraph or two must be capable of being used separately as a synopsis of the entire paper. It should not contain references to the bibliography. Manuscripts, in duplicate if possible, may be sent to any one of the four editors. All other communications to the editors should be addressed to the managing editor, Richard Arens, University of California, Los Angeles, California 90024.

Each author of each article receives 50 reprints free of charge; additional copies may be obtained at cost in multiples of 50 .

The Pacific Journal of Mathematics is published monthly. Effective with Volume 16 the price per volume (3 numbers) is $\$ 8.00$; single issues, $\$ 3.00$. Special price for current issues to individual faculty members of supporting institutions and to individual members of the American Mathematical Society: $\$ 4.00$ per volume; single issues $\$ 1.50$. Back numbers are available.

Subscriptions, orders for back numbers, and changes of address should be sent to Pacific Journal of Mathematics, 103 Highland Boulevard, Berkeley 8, California.

Printed at Kokusai Bunken Insatsusha (International Academic Printing Co., Ltd.), 7-17, Fujimi 2-chome, Chiyoda-ku, Tokyo, Japan.

PUBLISHED BY PACIFIC JOURNAL OF MATHEMATICS, A NON-PROFIT CORPORATION

The Supporting Institutions listed above contribute to the cost of publication of this Journal, but they are not owners of publishers and have no responsibility for its content or policies. 


\section{Pacific Journal of Mathematics}

\section{Vol. 26, No. $3 \quad$ BadMonth, 1968}

Leonard Asimow, Universally well-capped cones ................. 421

Lawrence Peter Belluce, William A. Kirk and Eugene Francis Steiner,

Normal structure in Banach spaces ..................... 433

William Jay Davis, Bases in Hilbert space.................... 441

Larry Lee Dornhoff, p-automorphic p-groups and homogeneous

algebras..................................... 447

William Grady Dotson, Jr. and W. R. Mann, A generalized corollary of the

Browder-Kirk fixed point theorem ....................... 455

John Brady Garnett, On a theorem of Mergelyan ................. 461

Matthew Gould, Multiplicity type and subalgebra structure in universal

algebras............................................. 469

Marvin D. Green, A locally convex topology on a preordered space . . . . . 487

Pierre A. Grillet and Mario Petrich, Ideal extensions of semigroups . . . . . . 493

Kyong Taik Hahn, A remark on integral functions of several complex

variables ... . . . . . . . . . . . . . . . . . . . . . . . . . . . . . . . . . . . 509

Choo Whan Kim, Uniform approximation of doubly stochastic

operators..................................... 515

Charles Alan McCarthy and L. Tzafriri, Projections in $\mathscr{L}_{1}$ and

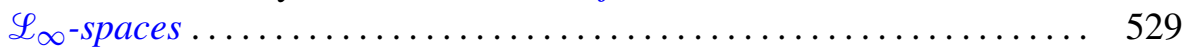

Alfred Berry Manaster, Full co-ordinals of RETs ................ 547

Donald Steven Passman, $p$-solvable doubly transitive permutation

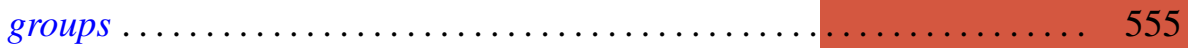

Neal Jules Rothman, An $L^{1}$ algebra for linearly quasi-ordered compact

semigroups ....................................... 579

James DeWitt Stein, Homomorphisms of semi-simple algebras .......... 589

Jacques Tits and Lucien Waelbroeck, The integration of a Lie algebra

representation ...............................

David Vere-Jones, Ergodic properties of nonnegative matrices. II ........ 601

Donald Rayl Wilken, The support of representing measures for $R(X) \ldots \ldots 621$

Abraham Zaks, Simple modules and hereditary rings .... . . 